\title{
Stability and Scrutiny Using (Ammi): Model of Bread Wheat Over the Years in Cold Arid Harsh Conditions of Kargil and Zanaskar (Ladakh)- India
}

\section{Mushtaq Ahmad ${ }^{1 *}$, Faizan Ahmad ${ }^{1}$, Ejaz Ahmad Dar ${ }^{2}$, Rizwan Rashid ${ }^{3}$, Shahnowaz Ahmad ${ }^{4}$, MH Khan ${ }^{5}$, Rohie Hassan ${ }^{6}$ and NR Sofi ${ }^{7}$}

${ }^{1}$ Mountain Agriculture Research and Extension, India

${ }^{2}$ Krishi Vigyan Kenner, Kargil, India

${ }^{3}$ Faculty of Horticulture, Shalimar-SKUAST-Kashmir, India

${ }^{4}$ Krishi Vigyan Kenner, Znaskar, India

${ }^{5}$ Saffron Research Station, Pampore-SKUAST-Kashmir, India

${ }^{6} \mathrm{Ph}$, D Scholar, OPGS University Churu, Rajasthan, India

${ }^{7}$ MRCFC KHUDWANI-SKUAST-Kashmir, India

*Corresponding Author: Mushtaq Ahmad, Mountain Agriculture Research and

Extension, India.
Received: August 14, 2020

Published: September 23, 2020

C All rights are reserved by Mushtaq

Ahmad., et al.

\begin{abstract}
Field experiments were carried out using 20 genotypes for 3 consecutive years (2017-2019) under two randomly completed conditions (Zanaskar Kargil or irrigation rainfall) to identify high-grain infarct-able wheat genotypes obtained by a single parameter. RBD with three copies in each environment. Combination testing of variation showed significant differences for the GE (genotypeenvironment) cardinal. The results of AMMI (additive main effect and multiplicative interaction) show that the first two AMMI (AMMI 1 - AMMI 2) are symbolic ( $<$ 0.01). It became clear that the division of whole squares was a major source of environmental impact variability, followed by interplay and genetic type effect. The GE cardinal genotype is three times greater than the effect, indicating the presence of different environmental groups. The AMMI Invisibility Value (ASV) lost the G12, G18, G13, G14 and G11 genotypes, respectively. Differentiation to SE is not a physical selection criterion because most incomplete genotypes do not provide the best yield performance and, therefore, grain yield and ASV can be considered simultaneously in a single parameter-free index. Depending on the rainfall and irrigation conditions, the G1 and G18 genes and the High Grain Genome Type Selection Index (GSI) were matched to the results of the biplot observation.
\end{abstract}

Keywords: Wheat; AMMI; SAV; Dry Cold Zone; Conflict; Observation; Genetics; Cargill; Reform

\section{Introduction}

Kargil is a district in the Indian state of Ladakh. It is bounded by Ladakh in the north-south, Jammu and Kashmir in the west, Leh district in the east, Gilgit-Baltistan in the north and Himachal Pradesh in the south. The Kargil district is located in the Himalayas and is known for its cool and temperate climate. Summer is hot with cold nights, winter is long and cold, temperatures often drop to $-15^{\circ} \mathrm{C}\left(5^{\circ} \mathrm{F}\right)$ and the recorded temperature is $\mathrm{D} 60^{\circ} \mathrm{C}\left(-76^{\circ} \mathrm{F}\right)$. It is $35 \mathrm{~km}$ from Kargil. Zanuskar Valley is cool. The Kargil District covers an area of $14,086 \mathrm{~km}^{2}$ (5,439 sq mi). He flows through the Suru River District. As per the 2011 census, Kargil district has a population of 140,802 [1]. It ranks 603 in India (out of a total of 640 ). The district's population density is 10 people per square kilometer (26/sq mi). Its population growth rate during the decade 2001 - 2011 was $20.18 \%$. There are 810 women for every 1000 men in Kargil, with a literacy rate of $71.34 \%$ (Wikipedia -2020). 
Stability and Scrutiny Using (Ammi): Model of Bread Wheat Over the Years in Cold Arid Harsh Conditions of Kargil and Zanaskar (Ladakh)India

The National Highway 1 connects Kargil with Srinagar Lake. Due to heavy snowfall in Zojila, the road is only open for traffic from May to December. The capital of Kargil is $204 \mathrm{~km}$ (127 miles) from Srinagar. There is a partially built road from Kargil south to Zanaskar. The total distance to Zanuskar is about $220 \mathrm{~km}$ (140 mi), which is open only from June to September. India and Pakistan intend to link the Pakistani town of Skard to Kargil by bus [1]. The main food crops in Kargil and Ladakh are wheat, barley and a little buckwheat, but the primary food is wheat, which is very challenging for scientists to increase the yield of major crops in all the tribal areas of Ladakh. Bread wheat (Triticum aestivum L.) is a staple food in Ladakh, especially Kargil and Sanaskar, so Kargil's primary goal is to improve crop and yield volatility (MAR and ES, 2007). The high yield of such soil structure, zanaskar and Kargil, is really a major contributor to this cold dry region of Ladakh, due to heavy snowfall with more than 5 or 6 widespread or specific reconstructions in the world, to identify the area's brown genetics. Once such information becomes available, we will conduct an experiment in Zanuskar and Kargil with very different climatic conditions (Wikipedia-2020: Kargil-Ladakh). Environments have a wide range of photoperiods and temperatures that cause large genotypes $(G)$ and environmental (E) cardinals (GEIs), especially in cold and arid regions with climate change every $10 \mathrm{~km}$. We (NBPGR) have received twenty entries from New Delhi, namely, cold tolerance and high earnings, and studied GE intervention from 2017 to 2019. GEI breeders (s) with large real crossover types are not valid for farmers, especially in high yielding ways. Average yield was high in all the environments. Understanding GEI and its physical bases is essential for effective breeding for high environments [2,3]. Most yield paths are only used to determine which crop produces the highest average seed yield, so merit is recommended for plant growers. Multilocation yielding efforts contribute to measuring environmental and GEI impacts [4]. The AME model is a useful method for GEI analysis and is used assessment of GEI in a variety of barley wheat and maize. GEI can be explained by the use of different models of AMMI, AMMI1 and AMMI2. In AMMI1, the X-coordinate represents the main effects (i.e.) and the effects of the $y$-coordinate interaction (IPCA1). Values placed close to the X-axis (IPCA1) are less likely to communicate than distance. Therefore, genotypes are more stable with smaller IPCA1 values. GGE Biplot Analysis (i.e. Genotype Type Main Effect (G) and Genotype $\times$ Environment Interaction (GIE) [5] is a useful tool for plant growers and geneticists to find maximum yields and stability in multiple locations. Extensive genetics of stabilization obtained by this method shows relatively stable yields and does not alter production conditions [6] by examining production processes, differences in yield differences in excavation, a zones and regions. There are a variety of parametric yoke and approaches, including GE cardinal monitoring, non-parametric and non-parametric, parametric procedures: (1) unified monitoring (regression monitoring and change), millage variation and rationing, and (2) multivariate observation Y (main) Component monitoring, ratios ent monitoring, canonical component monitoring, cluster observation and biplot monitoring). The general form of ANOVA is a conceptual model, so only the main effect is described [7]. The main problem with not explaining the multiplication model and the additive main effects is the major component consideration. Linear regression models [6,8] combine additive and multiplicative peripherals, analyzing the main effects and cardinals, but in general they confound the cardinal with the main effects [6]. The Additive Main Effects and Multiplicative Cardinal (AMMI) Model is a powerful multivariate method for multi-environment testing.

Because scientific scrutiny of diversity is ineffective, the Additive Principle Effects and Multiplicative Cardinal (AMMI) model has been found to be an effective tool for exploring the underlying patterns of cardinals in more detail. Ammi Effectiveness of genotypic responses to change in the environment must be effective wherever it is not [9], which is required for in vivo observational techniques. This technique, also known as FANOVA, takes into accounts both additive and multiplicative peripherals as integer least squares [10]. The AMMI model does not require this. It is a hybrid statistical model that incorporates both additive and multiplicative peripherals of the two-way genotype-environment data structure. It separates the additive main effects from the cardinal, which is analyzed as a series of multiplicative peripheral principal component observations and helps to represent the cardinal pattern [11]. The complex relationships between locations or genotypes are adequately represented in scatter gram [7]. Plots showing both genotypes and environments simultaneously can be very helpful in this regard and are called Biplots using AMMI In volatility Value (ASV) and average yield. The lower value of this parameter shows body genotypes with higher mean yield and volatility. Kargil is a district in the Indian state of Ladakh. It covers the entire length of Ladakh in the north-south, Jammu and Kashmir in the west, the district of Leh in the east, Gilgit-Baltistan in the north and Himachal Pradesh in the south. Kargil District is located in the Himalayas, which gives a cool, temperate climate. Summer is warm with cold nights, winter is long and cold, temperatures often drop to $-15^{\circ} \mathrm{C}\left(5^{\circ} \mathrm{F}\right)$

Citation: Mushtaq Ahmad., et al. "Stability and Scrutiny Using (Ammi): Model of Bread Wheat Over the Years in Cold Arid Harsh Conditions of Kargil and Zanaskar (Ladakh)- India”. Acta Scientific Agriculture 4.10 (2020): 02-09. 
Stability and Scrutiny Using (Ammi): Model of Bread Wheat Over the Years in Cold Arid Harsh Conditions of Kargil and Zanaskar (Ladakh)India

and the recorded temperature is $\mathrm{D} 60^{\circ} \mathrm{C}\left(-76^{\circ} \mathrm{F}\right)$. $\mathrm{Km}(35 \mathrm{mi})$ from Kargil town. The Zanaskar Valley is much colder than Kargil, but there is a source of irrigation from the glaciers. The Kargil district covers $14,086 \mathrm{~km}^{2}$ (5,439 sq $\mathrm{mi}$ ). The Suru River flows through the district. It is between 30 to 35 degrees north latitude and 75 to 77 degrees east west longitude. The district is divided into four high natural valleys: Suru Valley, Dras Valley, Indus Valley and Upper Sindh Valley of Kanji Nalla Valley. Zozila and Fotulla passes. Leh District is the gateway to the Kashmir Valley at an altitude of $3567 \mathrm{~m}$ and $4192 \mathrm{~m}$ above sea level and the entrance to the Kargil District. The highest peaks of Namkila and Penzila are called the Sky Pillars District. The district is surrounded by high Rocky Mountains, desert arid, snow-covered and natural vegetation [12,13]. It occupies a special place as it is at the height of the country. Height ranges from 8000 to 23000 feet. The topography of the region is a mountainous region with little or no vegetation. Since summer is short, only native barley or wheat is planted [14]. The GPSOF coordinates the Zanaskar latitude 33.8333 and longitude 76.833. The experimental layout in each environment was randomly generated with three replicates, complete block design. The climate of the region is classified as the coldest and hottest areas of Ladakh. The site at Zanaskar has irrigation facilities from the glaciers and the Cargill Mountain Research Station and Extension Station are somewhat irrigated by rain. Sometime using irrigation mechanism [15].

\section{Materials and Methods}

Experimental layout and genetic material: Field experiments were conducted for three consecutive years (2017 - 2019) at Kargil and Zanuskar under two different conditions (irrigation and rainfall) (Table 1) to determine the volatility of the 20 bread wheat genotypes. Each plot consists of five rows of 5 meters long. The seed density for your 2 is $400 \mathrm{~cm}$. The row spacing is $20 \mathrm{~cm}$. Data on seed yield were taken from the middle two rows of each plot. Seed yield was determined for each genotype in each test environment. Neighborhoods were treated as random factors, genotypes were considered fixed factors. The objectives of this study were (Identifying bread wheat genotypes with high average yield and imperfect yield performance in different environments for the semiridid regions of Zanaskar and (ii) studying the relationships, similarities and disparities between yields - violating statistics to calculate GE cardinal effects on yield. The genotype pool used in this study. The aim of this experiment is to improve the fundamental right and lilyhood of marginal and large farmers, because much of the land in Ladakh is underground and desert farmers have little land to grow their crops. So, our main aim of this experiment is to identify the high yielding genotypes of wheat in these challenging climatic conditions in the arid zone of Ladakh. Combined analyzes of variance, Bartlett's test for additive effect on grain yield, and Duncan's multiple comparison test were performed using MSTAT-C and SPSS statistical software. The observation of the additive principal effect and the multiplicative cardinal (AMMI) was performed using the model suggested by [16] as: $y i j=\mu+g i+e ~ j+=n=1 h \lambda n \alpha n i . \gamma n j$ + Rij. Where yz is the yield of the $\mathrm{i}^{\text {th }}$ genotype in the $\mathrm{j}^{\text {th }}$ environment, which is the grand mean, gi is the minus the grand mean of the $\mathrm{i}^{\text {th }}$ genotype, ej is the grand mean of the $\mathrm{j}^{\text {th }}$ environment, the min $n$ square $i^{\text {th }}$ genotype, and the PCA axis of the $j^{\text {th }}$ environment Remnants of origin and rim. A biplot based on single value decomposition (SVD) of GE only has a GE interaction and is called a GE biplot. In contrast, a Biplot G Plus is based on GE G and GE's SVD and is classified as a GGE Biplot [17]. GE Biplot is estimated for 20 genotypes tested in six environments. Clustering is calculated using an Agglomerate Ward's method [18] based on the hierarchical algorithm, and the cluster grouping result for the PCA score of the genotype PCA1 and PCA2 in the biplot of PCA1 and PCA2 were evaluated by the Iristat software for variation and mixed analysis.

\begin{tabular}{|c|c|c|}
\hline S. No & Code of entries & Entries \\
\hline 1 & G1 & IC 532168 \\
\hline 2 & G2 & IC 28729 \\
\hline 3 & G3 & IC 533744 \\
\hline 4 & G4 & IC 59563 \\
\hline 5 & G5 & IC 145936 \\
\hline 6 & G6 & IC 82288 \\
\hline 7 & G7 & IC 82431 \\
\hline 8 & G8 & IC 79015 \\
\hline 9 & G9 & IC 532851 \\
\hline 10 & G10 & IC 532096 \\
\hline 11 & G11 & IC 534770 \\
\hline 12 & G12 & IC 533766 \\
\hline 13 & G13 & IC 82328 \\
\hline 14 & G14 & IC 82388 \\
\hline 15 & G15 & IC 532310 \\
\hline 16 & G16 & IC 78782 \\
\hline 17 & G17 & IC 532772 \\
\hline 18 & G18 & IC 73334 \\
\hline 19 & G19 532442 \\
\hline 20 & G20 & IC 532160 \\
\hline
\end{tabular}

Table 1: Genotype code and the name of 20 bread wheat genotypes studied in this experimental research.

No. Code Name. 


\section{AMMI stability value (ASV)}

AMMI Stability Value (ASV) as described by [19] was calculated as follows: The weight given to IPCA1 is the value by dividing the sum of squares of IPCA1 by IPCA1.

ASV $=\lceil\lceil($ IPCA1 SUM OF SQURES)/(IPCA2 SUM OF SQURES)

(IPCA1 score) 2+ (IPCA score 2) 21

\section{Where SSIPACA1/SSIPCA2}

The larger the IPCA score, the negative or positive, the genotype is likely to adapt to certain environments. Smaller ASV scores indicate a more stable genotype in the environment.

\section{Genotype selection index (GSI): SS IPCA1}

The selectivity index known as GSI for each genotype is calculated based on the mean grain yield (RYi) and the AMMI stability value (RASVi) of the genotypes in the vicinity, which combine both the average grain yield and the stability index (GSIi):

GSIi = RASVi + RY.

\section{Results and Discussion}

\section{US examination of difference}

The combination of locations (irrigation (Januskar and rain Cargill) and years of combined observation (Table 2) resulted in significant differences $(\mathrm{P}<0.01)$ in the cardinal (locations and years) of the genotypes. Signal differences for the GE cardinals represent the environmental effects between the GE cardinal, gene entries, and the entries of Chandra., et al. In particular, we can go further and assess phenotypic instability $[9,25]$ compared to Duncan's multivariate test. Maximum grain yield belongs to the G genotypes 19, G16, G7 and G12 with an average seed yield of 595.94 and 590.98, 564.15 and $556.98 \mathrm{~g}$, respectively, of the minimum grain yield genotype G6 (332.96g) under irrigation conditions. The yield belongs to the G19 and G12 genotypes (292.39 and 290.17 gm2 with 1, respectively) and the minimum grain yield gene the form G6, G7 and G3 (137.91, 139.96 and 143.59 gm2-1, respectively). Annual crop genotypes that are icted for grain yield on a multi-location, multi-year basis often show the GE Cardinal, which complicates the selection or recommendation of materials. The advantages of the AMMI model of location-year combinations [10] or variants of the AMEI observation of the GE Cardinal are that they use the whole arrangement, impose limits on multiplicative terms, and at least square fit [28]. Within the limits, one can assume that any model matches the received data. However, the AMMI model has a good chance of predicting new sites and new years, thereby contributing to real forecast [22]. Gauch HG and Zobel RW [23] showed that AMMI1 is generally selective with IPCA1 and IPCA2 and that IPCA1 generally informs against major effects such as IPCA1 or IPCA2, or IPCA1 vs. IPCA2. The AMMI method is used for three main purposes. The first is model diagnosis, where AMMI is more appropriate for the initial statistical evaluation of yield trials, as it provides an analytical tool for determining sub-cases of other models when optimized for specific datasets [22]. Second, AMMI clarifies the G $\times \mathrm{E}$ cardinal and captures patterns and relationships of genotypes and environments [24]. The third use is to improve the accuracy of yield estimates. Gains with the accuracy of equivalent yield estimates have been obtained to increase the number of replicates by a factor of two to five [16,24]. Such gains can be used to reduce the cost of testing, to include more treatments in experiments, or to improve the ability to select the best genotypes by reducing the number of replicates. Using ANOVA, the yield is divided into a total square genotype, environment and GE cardinal. The GE cardinal is further divided by the observation of the major components (Table 3). The AMMI observation results showed that $11.54 \%$ of the total variability was justified by the GE cardinal, $81.05 \%$ by the environment and $3.83 \%$ by the bigenotype. The effect of environmental impact variation by dividing whole squares is followed by GE and genotype effect. GE Cardinal. The GE cardinal is further divided by the observation of the major components (Table 3). The AMMI observation results showed that $11.54 \%$ of the total variability was justified by the GE cardinal, $81.05 \%$ by the environment and $3.83 \%$ by the bigenotype. The effect of environmental impact variation by dividing whole squares is followed by GE and genotype effect. The GE cardinal genotype is three times greater than the effect, indicating the presence of different environmental groups. The percentage is justified by AMMI1 and AMMI2. Values of Cardinal Principal Peripheral (IPCA1, 2, 3 and 4) for genotypes and environments are displayed in table 4 and 5 . The contribution of IPC1 to the GE cardinal is greater than that of IPC2, IPC3 and IPC4, the greatest cardinal organism was found for genotype 19 , and the lowest cardinal 12 [24]. The ordination technique revealed high signal differences for IPC1, IPC2, IPC3 and IPC4. The first Cardinal Principal Component (IPC1) explained $42.54 \%$ of the GE variable, followed by IPC2 (34.68\%), IPC3 (15.31\%) and IPC4 (5.80\%). Therefore, AMMI1 and AMMI2 share $77.22 \%$ of the GE total. The values of the Cardinal Principal Peripheral (IPCA 1, 2, 3, 4) for genotypes and environments are shown in table 4 and 5. The contribution of IPC1 to the GE cardinal is larger than that of IPC2, IPC3 and IPC4, with the largest cardinal genome type 19 and the smallest cardinal 12 detected. 
Stability and Scrutiny Using (Ammi): Model of Bread Wheat Over the Years in Cold Arid Harsh Conditions of Kargil and Zanaskar (Ladakh)India

\begin{tabular}{|c|c|c|}
\hline Source of variation & Degree of freedom & Mean squares \\
\hline Year (Y) & 2 & $25468349^{* *}$ \\
\hline Location (L) & 1 & $6329726^{* *}$ \\
\hline $\mathrm{L} \times \mathrm{Y}$ & 2 & $929220 * *$ \\
\hline Error 1 & 12 & 6920 \\
\hline Genotype (G) & 19 & $45126^{* *}$ \\
\hline$G \times Y$ & 38 & $34873^{* *}$ \\
\hline $\mathrm{G} \times \mathrm{L}$ & 19 & $23885^{* *}$ \\
\hline $\mathrm{G} \times \mathrm{L} \times \mathrm{Y}$ & 38 & $21152^{* *}$ \\
\hline Error 2 & 228 & 3146 \\
\hline$\%$ C.V & & 16.57 \\
\hline
\end{tabular}

Table 2: Combined analysis of variance for grain yield over different rained and irrigated conditions.

**: Significant at $1 \%$ level of probability.

\begin{tabular}{|l|c|c|c|c|}
\hline Genotype & IPC1 & IPC2 & IPC3 & IPC4 \\
\hline G1 & -5.450 & 0.986 & 0.554 & -1.554 \\
\hline G2 & 6.289 & -3.976 & -2.588 & 0.876 \\
\hline G3 & -2.404 & 4.345 & 4.565 & 3.867 \\
\hline G4 & 4.365 & 2.543 & -1.667 & 1.434 \\
\hline G5 & 6.989 & 3.424 & 4.778 & -5.656 \\
\hline G6 & 2.453 & 12.768 & -4.889 & -2.487 \\
\hline G7 & -8.001 & -2.324 & -4.778 & 4.665 \\
\hline G8 & 2.001 & 8.745 & -1.770 & 3.799 \\
\hline G9 & -5.607 & -8.434 & -4.802 & -2.667 \\
\hline G10 & -2.887 & -2.456 & -4.551 & 5.432 \\
\hline G11 & 1.455 & 3.455 & -7.006 & -0.577 \\
\hline G12 & -1.451 & -4.786 & 7.444 & -6.338 \\
\hline G13 & -0.998 & 3.221 & 4.543 & 4.5676 \\
\hline G14 & 1.553 & -4.565 & -7.656 & -4.665 \\
\hline G15 & -2.678 & 5.677 & 0.789 & -2.098 \\
\hline G16 & -7.543 & -8.677 & 4.545 & 4.631 \\
\hline G17 & -1.336 & 5.888 & 5.675 & 0.667 \\
\hline G18 & -0.102 & -3.654 & 0.522 & -1.098 \\
\hline G19 & 6.678 & -4.975 & 4.453 & 6.110 \\
\hline G20 & 1.061 & -5.556 & 0.564 & 0.801 \\
\hline
\end{tabular}

Table 3: Values of cardinal principal peripheral (IPC) for bread wheat genotypes.

\begin{tabular}{|l|c|c|c|c|}
\hline SOV & DF & \%SS & \%SS & MSQ \\
\hline Genotype (G) & 19 & 766312 & $3.73 a$ & $47129^{* *}$ \\
\hline Environment (E) & 5 & 294661 & $83.04 \mathrm{a}$ & $3722419^{* *}$ \\
\hline G×E & 95 & 1471685 & $12.67 \mathrm{a}$ & $24299^{* *}$ \\
\hline IPC1 & 23 & 2089545 & $13.34 \mathrm{~b}$ & $48876^{* *}$ \\
\hline IPC2 & 21 & 984826 & $25.76 \mathrm{~b}$ & $44945^{* *}$ \\
\hline IPC3 & 19 & 484564 & $14.61 \mathrm{~b}$ & $23785^{* *}$ \\
\hline IPC4 & 17 & 125435 & $6.55 \mathrm{~b}$ & $7767^{*}$ \\
\hline Noise & 15 & 33640 & $1.98 \mathrm{~b}$ & 2647 \\
\hline Error & 240 & 711236 & $2.47 \mathrm{a}$ & 3136 \\
\hline Total & 359 & 32254354 & $4.93 \mathrm{a}$ & $47232^{* *}$ \\
\hline
\end{tabular}

Table 4: AMMI scrutiny of grain yield in bread wheat over rained and irrigated conditions.

\begin{tabular}{|l|c|c|c|c|}
\hline Environments & IPC1 & IPC2 & IPC3 & IPC4 \\
\hline E1 & -5.198 & -15.476 & -6.879 & 1.001 \\
\hline E2 & 17.552 & -2.899 & 3.342 & -0.789 \\
\hline E3 & -1.213 & 10.611 & -5.878 & 8.834 \\
\hline E4 & -3.874 & 8.312 & -5.098 & -1.764 \\
\hline E5 & -6.522 & -1.909 & 12.456 & 6.085 \\
\hline E6 & -2.443 & 3.989 & 3.630 & -13.001 \\
\hline
\end{tabular}

Table 5: Values of Interaction principal component (IPC) for environments.

AMMI incomplete value (ASV) for genotype

The AMMI model does not provide for quantitative invoice measurement and requires such measurements to calculate and rank gene types according to the yield, invoice, purchase and SV measurement suggested by others. In fact, ASV is a distance from zero (Cardinal Principal Component Scrutiny Axis 1) against IPCA2 scores of two-dimensional scatter gram. Since the IPCA1 score contributes greatly to the GE square sum (Table 6), the relative difference between the IPCA1 and IPCA2 scoresto be calculated, which replaces the relative contribution of the squares [25] to the total GE sum of IPCA1 and IPCA2. The distance from zero is determined using the Pythagorean Theorem). Although the main peripheral GESS does not cover much, the importance of the AMMI model is to reduce noise [22,23]. The AMMI Invisibility Value (ASV) lost the G12, G18, G13, G14 and G11 genotypes, respectively. Impossibility is not a physical selection criterion because most imperfect genotypes do not yield good yields, so consider grain yield and ASVs 
Stability and Scrutiny Using (Ammi): Model of Bread Wheat Over the Years in Cold Arid Harsh Conditions of Kargil and Zanaskar (Ladakh)India

in a parameter-free index at the same time. Genetic type selection index (GSI) selection should not be the only parameter, since most incomplete genotypes do not provide good yield performance [25], so there is a need for systems that combine average grain yield and invisibility. In this regard, ASV considers IPCA1 and IPCAA2 to justify most variants of the GV cardinal, so ASV's rank and average grain yield (RY) are included in the Genetic Type Selection Index (GSI). Low GSI is considered opaque with high grain yield. With the loss of G12 and G18 with normal genes and high grain yield, the Genetic Type Index (GSI) relies on precipitation and develops a condition that is consistent with the results of the biplot observation.

\begin{tabular}{|l|c|c|c|c|c|}
\hline Genotype & Mean yield & IPC1 & IPC2 & IPC3 & IPC4 \\
\hline G1 & 24 & -5.450 & 0.986 & 0.554 & -1.554 \\
\hline G2 & 28 & 6.289 & -3.976 & -2.588 & 0.876 \\
\hline G3 & 15 & -2.404 & 4.345 & 4.565 & 3.867 \\
\hline G4 & 18 & 4.365 & 2.543 & -1.667 & 1.434 \\
\hline G5 & 16 & 6.989 & 3.424 & 4.778 & -5.656 \\
\hline G6 & 20 & 2.453 & 12.768 & -4.889 & -2.487 \\
\hline G7 & 24 & -8.001 & -2.324 & -4.778 & 4.665 \\
\hline G8 & 22 & 2.001 & 8.745 & -1.770 & 3.799 \\
\hline G9 & 20 & -5.607 & -8.434 & -4.802 & -2.667 \\
\hline G10 & 21 & -2.887 & -2.456 & -4.551 & 5.432 \\
\hline G11 & 9 & 1.455 & 3.455 & -7.006 & -0.577 \\
\hline G12 & 12 & -1.451 & -4.786 & 7.444 & -6.338 \\
\hline G13 & 30 & -0.998 & 3.221 & 4.543 & 4.5676 \\
\hline G14 & 20 & 1.553 & -4.565 & -7.656 & -4.665 \\
\hline G15 & 13 & -2.678 & 5.677 & 0.789 & -2.098 \\
\hline G16 & 58 & -7.543 & -8.677 & 4.545 & 4.631 \\
\hline G17 & 18 & -1.336 & 5.888 & 5.675 & 0.667 \\
\hline G18 & 15 & -0.102 & -3.654 & 0.522 & -1.098 \\
\hline G19 & 20 & 6.678 & -4.975 & 4.453 & 6.110 \\
\hline G20 & 12 & 1.061 & -5.556 & 0.564 & 0.801 \\
\hline
\end{tabular}

Table 6: First and second IPC scores, ASVi and GSIi of genotype investigated.

\section{Pattern consideration}

The AMMI2 biplot (Figure 1) explained $77.22 \%$ of the GE Cardinal, making it a useful test for the Cardinals. Many genotypes and environments are scattered around Biplot. The genotypes appear to have distinct reproductions from the middle of the biplot. The Environmental Cardinal study revealed that the biplot diagram in Birm wheat was used to evaluate the specific reconstruction and to study their instability. Genetic Yield Depends on Rainy Weather 2017 Year (E2) weather has a different approach and has a highly positive cardinal. In addition, for two years 2012-2013 (E4 and E6), climate-dependent rainfall is negative, mostly earning the intermediate cardinal. Irrigation Weather 2012 (E3), at least cardinal, has its value close to zero. Neighbors E3, E4, E6, E2 and E1 have long vectors, mostly from the middle of the biplot. The first principle is the genetics G12 base, which is low and positive cardinal and high instability. The G19 gene has a high and negative cardinal principle and a low volatility. If the two vectors of the genotype have a smaller angle, the density is greater in both environments. The genotype at the center of the binocular axis means that the genotype is reproductive to the environment. The vertical length of the gene type vector in the environment vector shows the amount of variation of that genotype from that environment. When the length of the gene type vector is longer, the cardinal effect of that genotype on the environment is greater, The G3, G15 and G17 genotypes are unique 
Stability and Scrutiny Using (Ammi): Model of Bread Wheat Over the Years in Cold Arid Harsh Conditions of Kargil and Zanaskar (Ladakh)India

to the surrounding E4 and E6 because their angles are less than 90 and their GE is cardinal positive. Based on the problems described in figure 1, the biplot vector derived from the first and second principles, cardinal environments are three of the 20 genotypes studied in six environments. Irrigation and rainfall in 2017 (E3 and E4) are weather dependent, and rainfall in 2019 is weather dependent (E6) is a similar process. The two ecosystems (E1 and E5) that are irrigated in 2017 and 2019 are almost ecologically built and the 2017 rainfall is weather dependent. In other words, the genes of the G20, G2, and G19 genes have specific reproducibility using environmental E2 (rainfall). Depending on the weather in 2011), these genotypes have almost grain yield. Specific reconstructions of the G6, G8, G15, G3 and G17 environments using E1 and E5 (Irrigation Environment 2011 and Irrigation Environment 2013, respectively) and G9, G7 and G10 (2012) genotypes. Rain 2013 depends on the environment year (rainfall depends on the weather), and the G5 and G4 genotypes have a specific reconstruction of the environment (rainfall depends on the climate of 2011), but both genotypes have acceptable grain yield and are late genotype G1 environment E5 (A special rebuilding company using Irrigation Weather 2013). G11, G18, G14, G13 and G12 genotypes had a negative GE cardinal. The genotypes in the middle of the biplot have a zero cardinal; so does a simple reconstruction with different average grain yields. Only G18 genotypes with high performance and favorable returns are considered obscure. Based on the AMMI2 model, it is possible to recommend the G12 and G18 genotypes as incomplete genotypes based on rain-fed irrigation systems. Genetic analysis of the sample is determined in bulk form, thereby saving time and precision in interpretation and selection [7,24-29].

\section{Conclusion}

The Genetic Type-Environment (GE) Cardinal is an important and challenging task for plant breeders, geneticists and agronomists engaged in performance testing. The genotype-environment reduces the association between cardiovascular phenotype and gene values and combines different roles to be sensitive to environmental fluctuations in bias and gene effect estimates. Such features are not suitable for selection. Changes in yield and performance should be considered simultaneously to reduce the GE cardinal effect and make the selection of gene types more accurate and sophisticated. The results of this research show that the effects of the AMRI model on differential monitoring climate and genetic type I environmental cardinal are important. An examination of the cardinals of the gene type environment found that the four main boundaries were symbolic, and that the cardinal constituted 77.2 percent of the first parts of the entire square. Based on the AMMI2 biplot, genotypes 11 (WC-47359), 18 (WC-47472), 14 (WC-4611), 13 (WC-47388), and 12 (WC-47403) have common interests. Gene variants 12 (WC-47403) and 18 (WC-47472) are most violated based on ASV and GSI indicators genotypes 12 (WC-47403) and 18 (WC-47472) revealed the highest violation.

\section{Acknowledgement}

I extend my regards and pleasure to Dr Faizan (Sr Scientist and In charge Mountain Agriculture and extension station Kargil, and Ladakh hill council who provide us village support and some harsh conditions they manage our accommodations. we cannot complete this experiment without valuable suggestion and financial support, we all deeply extend our wishes to Dr Faizan because all credit goes to him. The authors would like to extend their sincere appreciation to the Researchers Supporting Project Number (RSP-2019/134), King Saud University, Riyadh, Saudi Arabia.

\section{Bibliography}

1. Ahmad M., et al. "Variability, Heritability and Genetic Advances in Wheat (Triticum aestivum L.) under Cold Arid Conditions of Kargil". International Journal of Current Microbiology and Applied Sciences 7.11 (2018): 1456-1461.

2. Vergas M., et al. "Interpreting treatment xenvironment interaction in agronomy trials". Agronomy Journals 93 (2001): 949960.

3. Thamson WE and SB Philips. "Methods to evaluate wheat cultivar testing environment and improve cultivar selection protocols". Field Crops Research 99 (2016): 87-95.

4. Saleem N., et al. "Genotype-environment interaction and stability analysis in Wheat (Triticum aestivum L.) for protein and gluten contents". Scientific Research and Essays 10.7 (2015a): 260-265.

5. Kılıç H. "Additive main effects and multiplicative interactions (AMMI) analysis of grain yield in barley genotypes across environments". Tarım Bilimleri Dergisi 20.4 (2014): 337-344.

6. Gabriel KR. "The biplot graphic display of matrices with application to principal component analysis". Biometrika 58 (1971): 453-467.

7. Hossain A., et al. "Biplot yield analysis of heat-tolerant spring wheat genotypes (Triticum aestivum L.) in multiple growing environments". Open Agriculture 3.1 (2018): 404-413. 
8. Ezatollah Farshadfar., et al. "AMMI stability value and simultaneous estimation of yield and yield stability in bread wheat (Triticum aestivum L.)". Australian Journal of Crop Science 5.13 (2019): 1837-1844.

9. Farshadfar E. "Incorporation of AMMI stability value and grain yield in a single non-parametric index (GSI) in bread wheat". Pakistan Journal of Biological Sciences 11.14 (2000a): 17911796.

10. Annicchiarico P. "Additive main effects and multiplicative interaction (AMMI) analysis of genotype location interaction in variety trials repeated over years". Theoretical and Applied Genetics 94 (1997): 1072-1077.

11. Babarmanzoor A., et al. "Genotype $\times$ environment interaction for seed yield in Kabuli Chickpea (Cicer arietinum L.) genotypes developed through mutation breeding". Pakistan Journal of Botany 41.4 (2009): 1883-1890.

12. Bajpai PK and Prabhakaran VT. "A new procedure of simultaneous selection for high yielding and stable crop genotypes". The Indian Journal of Genetics 60 (2000): 141-146.

13. Noorul Saleem., et al. "Stability analysis in Wheat: An application of additive main effects and multiplicative interaction". African Journal of Agriculture Research 10.4 (2015b): 295-300.

14. Eajaz Ahmad Dar., et al. "Declining Yield of Saffron in KashmirCan Environmental Changes Be Held Responsible: An Opinion. 1.2 (2018): 1-2.

15. Barah BC., et al. "The use of risk aversion in plant breeding; concept and application". Euphytica 30 (2001): 451-456.

16. Crossa J. "Statistical analysis of multilocation trials". Advances in Agronomy 44 (1990): 55-85.

17. Farshadfar E and Sutka J. "Biplot analysis of genotype environment interaction in durum wheat using the AMMI model". Acta Agronomica Hungarica 54.4 (2006): 459-467.

18. Fatemeh Bavandpori., et al. "Yield Stability Analysis of Bread Wheat Lines using Ammi Model". Agricultural Communications 3.1 (2016): 8-15.

19. Mohammadi R., et al. "Interpreting genotype- environment interactions for durum wheat grain yields using non-parametric methods (2007).

20. Pinthus MJ. "Estimate of genotypic value: A proposed method". Euphytica 22 (1973): 121-123.
21. Bajpai PK and Prabhakaran VT. "A new procedure of simultaneous selection for high yielding and stable crop genotypes". The Indian Journal of Genetics 60 (2000): 141-146.

22. Gauch HG. "Model selection and validation for yield trials with interaction". Biometrics 44 (1988): 705-715.

23. Gauch HG and Zobel RW. "AMMI analysis of yield trials". In: Kang MS, Gauch HG (editions) Genotype by environment interaction. CRC Press. Boca Raton, FL (1996).

24. Mohammadi R and Amri A. "Comparison of parametric and non-parametric methods for selecting stable and references adapted durum wheat genotypes in variable environments". Euphytica 159 (2008): 419-432.

25. Farshadfar E., et al. "Combining ability analysis of drought tolerance in wheat over different water regimes". Acta Agronomica Hungarica 48.4 (2020b): 353-361.

26. Maniruzzaman MZ Islam., et al. "Evaluation of yield stability of seven barley (Hordeum vulgare L.) genotypes in multiple environments using GGE biplot and AMMI model". Open Agriculture 24 (2019): 284-293.

27. Koutis K., et al. "Multi-environmental evaluation of wheat landraces by GGE biplot analysis for organic breeding". Agricultural Science 3.1 (2012): 66-74.

28. Zobel RW., et al. "Statistical analysis of a yield trial". Agronomy Journal 80 (1988): 388-393.

29. Freeman GH. "Modern statistical methods for analyzing genotype-environment interactions". In: M.S. Kang (edition.), Genotype $\times$ Environment Interaction and Plant Breeding, Louisiana State University Agricultural Center, Baton Rouge, LA (1990): 118-125.

\section{Assets from publication with us}

- Prompt Acknowledgement after receiving the article

- Thorough Double blinded peer review

- Rapid Publication

- Issue of Publication Certificate

- High visibility of your Published work

Website: www.actascientific.com/

Submit Article: www.actascientific.com/submission.php Email us: editor@actascientific.com

Contact us: +919182824667 